\title{
O conhecimento de si nas Litterae Indipetae ${ }^{1}$
}

\author{
Paulo Roberto de Andrada Pacheco \\ Universidade Federal de Ouro Preto \\ Marina Massimi \\ Universidade de São Paulo - Ribeirão Preto
}

\begin{abstract}
Resumo
Analisando um tipo específico de correspondência jesuítica - as Litterae Indipetae -, evidenciou-se um dinamismo de elaboração da experiência revelador de um modo de vida baseado no que comumente chamamos psicologia filosófica aristotélico-tomista. É a este vivido descrito nas cartas e a este modo de viver específico (com suas devidas implicações fundamentais) que se dedica este artigo, buscando responder à pergunta: em que medida o conhecimento de si expresso a partir de lugares comuns próprios do gênero de correspondência que são e da forma de pensar dos jesuítas (num âmbito histórico-cultural-institucional peculiar) pode interessar à psicologia moderna? Resulta desta investigação, que a elaboração do conhecimento de si, neste âmbito preciso, parte do pressuposto de que o homem é uma unidade (corpo e alma, razão e fé, sensação e intelecção) e de que, vivendo ordenado (em si mesmo e no mundo que o circunda), realiza-se o seu ser por analogia ao Ser Divino.
\end{abstract}

Palavras-chave: conhecimento de si; psicologia filosófica; companhia de jesus; litterae indipetae

\begin{abstract}
The knowledge of himself in the Litterae Indipetae. By the analysis of a specific type of Jesuitical correspondence - the Litterae Indipetae -, a dynamism of the experience's elaboration was outstanding, revealing a modus vivendi (way of living) based on Aristotelic-Thomist philosophical psychology, name under which this praxis has been usually referred to. This article is dedicated to this lived experience described in the letters and to this specific modus vivendi (with its due basic implications), searching to answer this question: in which measure does the category of knowledge of himself expressed, starting from proper common place as specific type of letters and of the way of thinking of the Jesuits (in a particular historical-cultural-institutional scope) can be of interest to modern psychology? It results from this inquiry that the elaboration of the experience of knowledge of himself, in this scope, starts from the assumption that man is an unit (body and soul, reason and faith, sensation and intellection) and that, living in an orderly way (in itself and in the world that surrounds it), fulfills its being by analogy to the Holy Being.

Key-words: knowledge of himself; philosophical psychology; society of jesus; litterae indipetae
\end{abstract}

El que ignora qué es el hombre no puede usar del hombre; y así, quien no se conoce a sí mismo no podrá usar de sí mismo, y, por consiguiente, de las demás cosas que le tocan. (Nieremberg, 1640/1957, p. 249)

$\mathrm{E}$ m que medida a experiência de conhecimento de si presente na forma mentis (forma de pensar) e, especialmente, na educação a que eram submetidos os jesuítas dos séculos XVI e XVII, expressa em um gênero de correspondência epistolar particular, pode interessar à psicologia hodierna?

Esse período, na história do pensamento ocidental, corresponde ao momento de uma ruptura na relação com o divino, que havia sido cultivada durante toda a Idade Média. Trata-se, sem dúvida, de uma característica bastante interessante da realidade institucional da Companhia de Jesus, exatamente porque consegue manter certa tensão humana nesse relacionamento com o mistério, num momento em que este se enfraquecia progressiva e definitivamente.

Evidentemente, estamos tratando de uma questão limítrofe, em que campos do saber bastante diferenciados, necessariamente, entram em um diálogo, cujos frutos terão a medida exata do deixar-se provocar por esses homens afastados de nós no tempo e na mentalidade.

Trata-se de uma realidade cultural e institucional significativa, na medida em que podemos considerar a Companhia 
de Jesus como uma das responsáveis pela construção, transmissão e preservação da cultura brasileira nos níveis antropológico-filosófico e teológico. Nosso interesse é evidenciar a compreensão que, neste âmbito peculiar, se tinha de conhecimento de si e, mais do que isso, como os jesuítas se aplicavam a esta prática.

Nossa principal fonte documental foram as chamadas Litterae Indipetae: cartas nas quais jovens jesuítas dos séculos XVI e XVII solicitavam ao Padre Geral da Companhia de Jesus o envio em missão nas Índias (como eram, genericamente, designados os territórios de missão no âmbito cultural e institucional com o qual trabalhamos). Atualmente, estas cartas encontram-se conservadas no Archivum Romanum Societatis Iesu (ARSI), em Roma. Pode-se dizer que são fontes que interessam, na medida em que contêm exemplos das modalidades de elaboração da experiência pessoal no que respeita ao processo eletivo a que eram educados os jesuítas; além de dados sobre o indipetente (como idade, escolaridade, atividade que exercia na Ordem, etc.); bem como conteúdos edificantes próprios do gênero de documento que são.

As cartas Indipetae podem ser descritas como sendo representantes de um gênero retórico próprio, que obedece às regras da ars dictaminis (arte de ditar), sendo que se trata de uma produção particular que não pode ser compreendida isoladamente, mas dentro de um contexto sociocultural claramente distinto de outros.

Outrossim, sabemos que no Archivum Romanum Societatis Iesu (ARSI) existem 14.067 cartas Indipetae do período que vai do ano de 1583 ao ano de 1770, escritas por 5.167 jesuítas europeus das mais diversas nacionalidades. Com um universo assim grande de cartas, foram-nos necessários alguns recortes significativos: alguns impostos pela própria limitação de documentos a que tivemos acesso, outros impostos pelos limites do método.

Diante desse universo, optamos por trabalhar com um número reduzido de cartas espanholas, escritas no período do generalato do Padre Cláudio Aquaviva - entre 1581 e 1615. Além disso, optamos por trabalhar em duas vertentes de análise: uma macro-histórica, interessada em avaliar as mudanças no tempo, do ponto de vista institucional, do uso de topoi (lugar comum), tais como indiferença, vocação, desejo, martírio, etc., analisando 23 correspondências enviadas da Espanha, por 23 diferentes jesuítas no período do referido generalato (uma por ano e de acordo com a disponibilidade de fontes referentes ao recorte escolhido); e uma micro-histórica, interessada em avaliar essa mesma mudança no nível pessoal, analisando 3 correspondências enviadas por um mesmo jesuíta espanhol, dentro do supradito período histórico.

Nosso objetivo geral é mostrar as categorias filosóficas, teológicas e, se assim podemos chamá-las, psicológicas, que sustentam - nas cartas - um vivido particular, ou seja, a encarnação de determinadas normas e teorias. Estas categorias emergiram da análise dos topoi cultural e institucionalmente determinantes do protocolo formal de redação daquelas cartas. Um protocolo regulado pela longa tradição da ars dictaminis.

É justamente no âmbito do saber sistematizado em torno do que comumente se chama psicologia filosófica aristotélicotomista, bem como dos estudos dos diferentes gêneros de documentos produzidos neste âmbito - manuais de filosofia, tratados de espiritualidade, cartas, etc. - e das pesquisas abrangendo esse saber que se assenta este texto.

\section{Do conhecimento de si: desejo, vocação, desengano...}

Que os jesuítas eram formados a um trabalho de investigação acerca de si mesmos é evidente, quando observamos os importantes textos reguladores desta ordem religiosa: desde as Constituições, até os Exercícios Espirituais, passando pelas correspondências trocadas internamente e pelos escritos espirituais, que tiveram seu auge de produção entre o final do século XVI e início do XVII. Porém, que dentro desse esforço possamos encontrar uma preocupação com a ordenação das paixões (dos apetites sensitivos), ou com a identificação da vontade de Deus como origem de um desejo (e, portanto, vocação ou inspiração divina, diferente de toda tentação ou engano), ou com a aplicação das potências humanas (os sentidos, a razão e a vontade), não é tão evidente quanto parece.

Massimi e Prudente (2002) afirmam que o termo desejo, dada sua constante repetição nas cartas, muitas vezes faz parecer que seja ele "o verdadeiro protagonista do escrito, o objeto que move a pedir insistentemente” (p. 25). De fato, essa recorrência não aparece só nas Indipetae: trata-se de um termo comum à forma mentis do jesuíta (Certeau, 1982; Massimi \& Prudente, 2002; Pécora, 1994) que encontra, por exemplo, nos Exercícios Espirituais o estabelecimento de um protocolo de ordenação do desejo; ou no Relato de Santo Inácio a experiência-modelo (Marin, 1996) de um desejo que saiu da desordem (desejos mundanos ${ }^{2}$ ) para chegar à ordem (desejo de imitar os santos ${ }^{3}$, desejo de ser útil ${ }^{4}$ ) por meio da graça de Deus e do trabalho ascético; ou no Diário de Moções Interiores, onde o termo aparece de novo como experiência de aplicação dos instrumentos ordenadores com o intuito de se fazer uma eleição mais adequada à glória de Deus e ao fim da Companhia; ou mesmo nas Constituições, nas quais encontramos o desejo descrito, por exemplo, como um dos pontos a serem examinados no momento da entrada na Ordem ${ }^{5}$, ou como aquilo que faz do jesuíta um jesuíta de fato.

Seja como for, nessa perspectiva particular em que aparece o termo desejo, interessa muito que se saiba se é ordenado ou se é desordenado, se é uma inspiração vinda de Deus, ou se é fruto de uma tentação do "Inimigo da natureza humana”. Um desejo desordenado é um desejo que não é teleologicamente orientado, entendendo-se esse fim a que se orienta como “o Fim”, ou seja, “a honra e glória de Deus nosso Senhor” e a "salvação espiritual das almas”: 
Para que o Criador e Senhor aja mais seguramente em sua criatura, se acontecer que esta alma esteja presa e inclinada a uma coisa de maneira desordenada, lhe convém reagir com todas as suas forças (...). Assim, por exemplo, se ela está presa à busca e posse de um cargo ou um benefício não pela honra e glória de Deus nosso Senhor nem pela salvação espiritual das almas, mas por uma sua vantagem pessoal e por seus interesses temporais, ela deve se ligar ao oposto, insistindo bastante nas suas orações e outros exercícios espirituais, e pedindo o contrário a Deus nosso Senhor; quer dizer, que ela não quer este cargo, este benefício nem nenhuma outra coisa, a menos que sua divina majestade, ordenando seus desejos, não mude nela seu primeiro vínculo; de tal maneira que o motivo para desejar ou possuir tal ou tal coisa seja unicamente o serviço, a honra e a glória de sua divina majestade. (Loyola, século XVI/1991, p. 56, EE. 16) ${ }^{6}$

O desejo ordenado é, portanto, aquele que se conforma à Vontade de Deus até o ponto da identificação entre o exercitante e o Cristo, de quem ele mais se aproxima e se une na medida em que afasta o espírito das muitas coisas do mundo e se aplica totalmente a apenas uma coisa: "o serviço de seu Criador e o proveito de sua alma”, usando "mais livremente suas faculdades naturais para buscar com cuidado aquilo que tanto deseja” (Loyola, século XVI/1991, p. 62, EE. 20). E, o que o homem tanto deseja, é "louvar, reverenciar e servir a Deus nosso Senhor e por meio disso salvar sua alma” (Loyola, século XVI/1991, p. 62, EE. 23), como o afirma o Princípio e Fundamento, ao descrever a verdadeira vocação do homem.

E quanto ao termo vocação, encontramos um sem-número de referências a ele nos mais diversos textos da Companhia de Jesus. A primeira vez em que aparece é em um dos Documentos de Fundação, quando, relatando a maneira como se instituiu a Ordem, se diz:

Estávamos divididos em pareceres e opiniões que divergiam com relação ao nosso estatuto, e tínhamos um só e mesmo pensamento e vontade, que era buscar "o bom prazer e a perfeita vontade de Deus”, segundo a visada de nossa vocação. (Loyola, século XVI/1991, p. 277)

E qual é essa nossa vocação? Em carta enviada aos Padres e Irmãos de Coimbra, aos 07 de maio de 1547, Inácio escreve:

Considerai o que é vossa vocação, vereis que aquilo que entre os outros não seria pouca coisa, sê-lo-ia, no entanto, para vós. (...) Ainda mais, para que vosso espírito ou vosso amor não fossem pegos por esses baixos interesses (...), Ele [Deus] quis que vós pudésseis vos voltar e vos doar inteiramente ao fim para o qual Ele vos criou, sua honra e sua glória, vossa salvação e o socorro de vosso próximo. (Loyola, século XVI/ 1991, p. 695)

A honra e a glória de Deus e a salvação das almas, em "não importa qual parte do mundo onde se espera um maior serviço de Deus e uma maior ajuda para as almas” (Loyola, século XVI/1991, p. 468, Const. §304): eis a vocação do jesuíta, nos termos em que a define também o texto das Cons- tituições. Nessa vocação, é pedido de um jesuíta perseverança e obediência. Porém, aquilo que interessa sobremaneira é confirmar a origem divina do chamado, como se lê no exercício 172:

É necessário (...) ver se a eleição não foi feita como se deve e de maneira ordenada, sem vínculos desordenados (...). Uma tal eleição não parece ser uma vocação divina, porque é uma eleição desordenada e tortuosa; muitas pessoas se enganam nisso, fazendo de uma eleição tortuosa e má, uma vocação divina (...). Toda vocação divina é sempre pura e nítida, sem que nada da carne ou de qualquer outro vínculo desordenado se misture. (Loyola, século XVI/1991, p. 140, EE. 172)

$\mathrm{O}$ que permite uma certeza acerca da origem da vocação é primeiramente um conhecimento seguro de si mesmo, que dá ao jesuíta a possibilidade de, atento aos movimentos da alma, distinguir o que vem de Deus daquilo que vem do Inimigo:

O próprio de Deus e de seus anjos é dar, nas suas moções, uma verdadeira letícia e alegria espiritual, afastando toda tristeza e perturbação que o inimigo suscita. O próprio deste último é lutar contra esta letícia e essa consolação espiritual, apresentando razões aparentes, sutilezas e contínuos sofismas. (Loyola, século XVI/1991, p. 232, EE. 329)

Nesse sentido, é necessária também uma atenção ao desenrolar dos pensamentos contíguos aos desejos experimentados: se, no seu prolongamento, desde o princípio se localizam bons fins e uma orientação ao Bem, “é sinal do bom anjo” (Loyola, século XVI/1991, p. 234, EE. 333); do contrário, “é um sinal claro que isso vem do mau espírito” (p. 234, EE. 333). Esses exames atentos e outros tantos que se seguem no texto dos Exercícios Espirituais têm por objetivo facilitar o caminho para a eleição. E, nesse ponto, entram, por exemplo, as tópicas encomendar, considerar, dar as razões e desengano.

Nas "Seis maneiras de se fazer uma sã e boa eleição", Inácio lembra que é necessário "pedir a Deus nosso Senhor que ele queira mover minha vontade e colocar na minha alma aquilo que devo fazer (...), refletindo bem e fielmente com minha inteligência” (Loyola, século XVI/1991, p. 144, EE. 180) e, além disso, sugere que se deve "considerar, refletindo, quantas vantagens e proveitos decorrem para mim do fato de ter (...) em vista somente o louvor de Deus nosso Senhor e salvação de minha alma” (p. 144, EE. 181). Ao final desse trabalho, "olharei para qual lado a razão inclina mais” (p. 144, EE. 182): “É, portanto, após uma maior moção da razão, e não após alguma moção dos sentidos, que é necessário tomar a decisão concernente à coisa visada” (p. 144, EE. 182). Ou seja, para se conhecer bem a origem de um desejo é preciso, primeiro, pedir a Deus a graça da compreensão, quer dizer, “encomendar a coisa a Deus” e, em seguida, ter claras para si as razões que o movem ${ }^{7}$.

O homem deve se encomendar a Deus, confiar-se a Deus que não o engana, e desconfiar de si mesmo, porque as paixões e os sentidos sempre podem enganar (Arias, 1588/1600). 
Porém, nesse trabalho o homem sofre muitas tentações, de tal forma que é importante que ele veja e experimente que sozinho não as pode vencer e que, portanto, precisará do favor divino, desconfiando de suas próprias forças. Só o favor divino conferirá eficácia e bons efeitos aos meios empregados em qualquer empresa à qual se dedique o homem. E é, nesse sentido, muito importante que o homem tenha sempre presente - considere - o fim para o qual tanto ele, quanto toda a realidade, foram criados: "Considerai o fim porque Deus faz todas as boas obras, que é para honra e glória sua” (Arias, 1588/1600, p. 78).

Nesta mesma via, escreve, anos mais tarde, Nieremberg (1640/1957):

O sedento, para satisfazer a sede, deve ir a uma fonte de águas; e o homem, para alcançar o sossego de seu coração, deve buscar a Deus: o divertir-se com outras criaturas, querendo com elas apascentar seu gosto, não é mais que comer sal que aviva sua sede e apetite e se abrasem as entranhas. (p. 243)

O trabalho do desengano - de ir à verdadeira fonte que mata a sede e dá sossego ao coração - é um trabalho que requer "a assistência da razão, potência suficiente para corrigir os enganos” (Pécora, 1988, p. 302) dos sentidos. É um trabalho de reconhecimento do essencial, do Ser real de todas as coisas, escondido por trás do variável e instável de sua forma presente. Este trabalho requer um olhar que se estende da origem ao destino de toda a realidade: onde origem e destino coincidem, na medida em que, num dinamismo histórico-teleologicamente-orientado - escatológico, para ser breve -, ambos os pólos remetem ao Doador do Ser, que cria a realidade ininterruptamente - tam Pater nemo (ninguém é tão pai) (Tertullien, século II/1906, p. 162) - e a leva à sua perfeição final.

Havíamos dito, em outra parte, que é somente "no momento das escolhas definitivas que se observa o sucesso ou o erro” (Pécora, 1998, p. 195): uma escolha definitiva - ou uma eleição feita de forma ordenada - coincide com a conformidade com "uma vocação divina” (Loyola, século XVI/1991, p. 140, EE. 172), e a vontade divina nunca engana. Chega-se à esta escolha definitiva, chega-se a fazer uma eleição ordenada, livre dos enganos da paixão, na medida em que se aplicam adequadamente as potências da alma racional: a verdadeira eleição é aquela que tem como fim último a manutenção da relação causal Criador-criatura. O desengano é, em termos gerais, a aceitação da Graça, o reconhecimento dos "sinais do olhar de Deus, capaz de encontrar na matéria a marca do zelo da Providência” (Pécora, 1988, p. 313). O desengano, enfim, pode ser descrito como aquela dinâmica de reconhecimento, no desejo, do côncavo infinito que apenas um convexo adequadamente infinito seria capaz de preencher: querer preencher a ausência com outros objetos, pelo contrário, é ficar no engano.

Nieremberg (1640/1957) em seu De la diferencia entre lo temporal y eterno, a fim de desenganar o leitor, apresentan- do-lhe a memória da eternidade, deixa claro: "sobretudo, a maior calamidade da vida humana não é a peste ou a fome, mas as paixões humanas não colocadas sob o uso da razão" (p. 145). Assim, o homem deve distinguir bem o que é temporal do que é eterno: enquanto os bens temporais são meios, os eternos são fins.

Mais à frente, no mesmo livro, o autor lembra: "Abre os olhos e repara para quê nasceste neste mundo”, desenganate e lembra-te de que "nasceste para Deus, e não para nada que seja menos que Deus e servir a Deus”, foi para isto que te foi dada a vida, "para isto te tiraram do não ser ao ser e passaste do nada à qualidade de criatura racional” (Nieremberg, 1640/1957, p. 240). O homem se desenganará na medida em que "por Deus anelar somente", na medida em que não tiver “inclinação a outra coisa”, e buscar a Deus com “todas as potências de sua alma e forças de seu corpo e afetos de seu coração" (Nieremberg, 1640/1957, p. 242).

Percebe-se daí que, não só se devem aplicar a razão e a vontade neste trabalho, mas também os sentidos - abre os olhos -, as potências da alma sensitiva: trata-se da aplicação dos sentidos a que se refere tantas vezes Inácio de Loyola, por exemplo, nos Exercícios Espirituais. A mesma, inclusive, que lhe permitiu, no dia 04 de março de 1544, fazer a seguinte nota no seu Diário de Moções Interiores:

Não sabendo por quem começar, e me fixando primeiramente em Jesus, me parecia que ele não se deixava ver ou sentir claramente, mas de uma certa maneira obscura; e me fixando sobre a Santíssima Trindade, me parecia que ela se deixava sentir e ver mais claramente ou luminosamente. Começando, e continuando com sua divina Majestade, cobri-me de lágrimas, soluços, amor tão intenso que eu tinha a impressão de ser extraordinariamente unido a seu amor tão luminoso e tão doce. De tal forma que esta intensa visita e amor me parecia insigne e excelente comparada às outras visitas (Loyola, século XVI/ 1991, p. 348, § 105)

Os sentidos, para que não se enganem, devem, pois, se voltar a um objeto adequado e, após sua aplicação, se deve considerar a experiência a que se chegou, se deve atingir um juízo racional acerca do sentimento experimentado finalmente.

Porém - e importa que se compreenda bem - este uso dos sentidos deve ter uma referência de perfeição, para que não se incorra no engano a que são levados naturalmente os sentidos:

Aquele que, no uso de seus sentidos, quiser imitar a Cristo nosso Senhor, se recomendará na oração preparatória, à sua divina Majestade; e após ter considerado cada um dos sentidos, dirá uma Ave Maria ou um Pai Nosso. Aquele que, no uso dos sentidos, quiser imitar Nossa Senhora, se recomendará a ela na oração preparatória para que ela lhe obtenha de seu Filho e Senhor a graça para isso; depois, após considerar cada um dos sentidos, dirá uma Ave Maria. (Loyola, século XVI/1991, p. 178, EE. 248) 
Além disso, na aplicação dos sentidos, ao se considerarem as coisas de Deus, deve-se fazer como alguém que entra na casa de um senhor e olha as coisas que existem aí, e ouve o que ali se fala, e cheira os suaves odores que ali existem, e saboreia os bons manjares que se oferecem; e finalmente toca com as mãos as coisas belas e preciosas que ali se mostram. (Villanueva, 1608, p. 28/1)

De tal forma que, quando se fala de sentidos, nesta perspectiva, deve-se entender que não se trata de uma vidência como aquela da visio Dei mística, puramente contemplativa e passiva, mas de uma característica eminentemente jesuítica: o fato de que, como o diz Jerônimo de Nadal, o jesuíta é o contemplativo em ação, é o homem da militância missionária, o homem da ação; de tal forma que é na ação que ele se conhece, é na aplicação de suas potências no contato com a realidade que ele conhece a si mesmo e a realidade. Aplicar os sentidos não é por assim dizer, é concreto (Pécora, 1988).

O conhecimento de si mesmo é concebido em função da praxe, pois conforme assinala Vieira (1993) num de seus sermões: "neste mundo racional do homem, o primeiro móbil de todas as nossas ações é o conhecimento de nós mesmos” (p. 607). E reitera:

Eu digo que são filhas do pensamento e da idéia, com que cada um se concebe, e conhece a si mesmo. O conhecimento de si mesmo, e o conceito que cada um faz de si, é uma força poderosa sobre as próprias ações. (Vieira, 1993, p. 607)

Além disso, nesta aplicação dos sentidos, o critério para distinguir se o uso foi eficaz é o resultado a que se chega: "Quando a pessoa que se exercita [na aplicação dos sentidos] não encontra ainda o que deseja, como, por exemplo, lágrimas, consolações, etc., é proveitoso fazer uma mudança na comida, no sono e nas outras maneiras de fazer penitência” (Loyola, século XVI/1991, pp. 100-102, EE. 89).

As lágrimas que se experimentam, a indignidade e a falta de virtudes suficientes para o trabalho missionário que se descobre em si mesmo não são apenas aquela falsa modéstia sentimental a que muitos seriam levados a crer, ou, quem sabe, apenas uma tentativa de persuasão sem verdade - uma pura argumentação sofista com intuito de convencimento pela moção de determinados sentimentos: há, sim, o desejo de moção de determinadas paixões no destinatário (o movere da oratória ciceroniana), mas, na medida do possível, sempre com palavra "plena animi, plena spiritus, plena doloris, plena veritatis” (Cicéron, 55 a.C./1966, p. 36).

Um outro aspecto deste conhecimento de si precisa, antes de avançarmos, ser bem compreendido. Se analisarmos a estrutura dos Exercícios Espirituais, veremos que ele é organizado e pensado como instrumento, em síntese, com este fim específico: conhecer a si mesmo para bem eleger a vontade de Deus.

A partir de um trecho de Honor del gran patriarca san Ignacio, escrito por Nieremberg (1645), poderemos compreender melhor esta passagem. Neste livro, o autor, contando a história de santidade do fundador da Companhia de Jesus, chega ao ponto em que começa a descrever a vida de oração de Inácio de Loyola, e escreve:

Para chegar a tão alto ponto da oração, de tal maneira domou e quase extinguiu seus afetos santo Inácio, que não parecia homem, com tal paz de suas paixões sujeitas à razão, tão incontrastável, que parecia espírito puro. Coisa tão admirável (...) o perfeitíssimo domínio que teve santo Inácio sobre os movimentos do coração, e todas suas paixões. Regia-as todas, não para mal, sim por necessidade e razão, enquanto serviam à virtude; e que isto em tal grau, e tão conatural nele, que julgaram os Médicos que havia mudado totalmente o temperamento, porque como por natureza fosse ardente e colérico e como um fogo, o qualificavam de frio e fleumático; e isso se devia apenas ao fato de que trocara sua condição, transformando-se segundo a condição do corpo em Cristo Jesus, seu amado, deixando de ser colérico para ser manso e humilde de coração, como de si mesmo disse o Senhor. (Nieremberg, 1645, pp. 40-41)

Só chega a domar os afetos aquele que se conhece, que sabe como se movem suas paixões, aquele que percorreu a topografia de sua alma como quem, com a ponta do dedo, assinala num mapa, os caminhos e descaminhos que deverá percorrer. Só chega a "vencer-se a si-mesmo e ordenar sua vida sem se decidir por nenhum vínculo que seja desordenado” (Loyola, século XVI/1991, p. 62, EE. 21) o homem que, como princípio e fundamento, sabe que "é criado para louvar, reverenciar e servir a Deus nosso Senhor e, assim, salvar sua alma” (Loyola, século XVI/1991, p. 62, EE. 23), e que, se dedicando a uma série de práticas e exercícios espirituais, conhece a si mesmo - sua alma - como a um livro aberto e como a palma de sua mão.

Numa edição dos Exercícios Espirituais, publicada na França, em 1673, pela casa editorial chez Michael Cnobbaert, a L'enseigne de S. Pierre, encontramos diversas ilustrações que ajudam o exercitante no trabalho de compositio loci (composição de lugar). Entre as figuras, encontram-se, no início do Exame Particular a figura de um livro em cujo cabeçalho se encontra a frase Ut sciat: para conhecer. Já, pouco antes do Exame Geral, aparece a imagem de uma mão, onde, em cada dedo está representado um dos cinco pontos referentes à maneira de fazer o exame geral ${ }^{8}$, e, na palma da mão está escrito Anima mea in manibus meis semper: minha alma está sempre em minhas mãos (Salmo 119[118], versículo 109). Enquanto que o Exame Particular se refere àquele cuidado cotidiano com um "pecado particular ou defeito que se quer corrigir ou emendar” (Loyola, século XVI/1991, p. 64, EE. 24), implicando a constante aplicação das faculdades todas da alma neste conhecimento - do nível vegetativo ao racional; o Exame Geral repassa, um a um, os pecados todos - do pensamento, da palavra e da ação - que se pode cometer. Conhecer-se a si mesmo quer, pois, dizer apenas conhecer sua capacidade de pecado? Não, se se compreender que por meio deste conhecimento - que é o início apenas, a Primeira Semana, dos Exercícios Espirituais - o homem se purifica a fim de melhor entrar nos exercícios que serão propostos em seguida. O homem não só se purifica, mas se desengana e evita 
seja o excessivo amor próprio, seja a desconsideração de sua própria natureza, que "nos impede[m] a verdadeira liberdade do puro serviço divino” (Aquaviva, 1583, p. 5). Seraphin Bonaventura Coçar, por exemplo, refere-se a isso quando relata, em Indipeta enviada no dia 02 de maio de 1583, que

Ya estoy libre gloria al S.or de toda melancholia, y muy lexos della, que alfin no me era natural, y aunque algunas vezes estoy de malagana (cosa que por todos passa) pero es de tal calidad, que el exercicio corporal, y ocupacion exterior, de que ay abundancia en las Yndias, del todo me la quita. (ARSI, Indipetae Hispanae, FG 758, carta n. 4)

Livre de toda melancolia não-natural: é o próprio Inácio que lembra, nos Exercícios Espirituais, antes de dar entrada à Segunda Semana, que “o exame particular se fará para suprimir defeitos e negligências” (Loyola, século XVI/1991, p. 102, EE. 90).

Só então, terá início a Segunda Semana, quando o jesuíta é chamado a contemplar "o apelo do (...) rei eterno" e, nesse sentido, é ajudado a fazer eleição a partir da contemplação da Encarnação e do Nascimento. Pouco antes dos exercícios desta semana, Inácio propõe a seguinte oração para aqueles que querem "se distinguir no serviço de seu rei eterno e Senhor universal” (Loyola, século XVI/1991, p. 106, EE. 97):

Quero e desejo, e é minha decisão determinada, desde que seja vosso maior serviço e vosso maior louvor, vos imitar suportando todos os ultrajes, todas as repreensões e toda pobreza, tanto efetiva, quanto espiritual, se vossa santíssima Majestade quer me escolher e me receber nesta vida e neste estado. (p. 106, EE. 98)

Um homem será capaz de eleger um modo de vida, um estado de vida mais adequado e próximo do fim, da realização que deseja e para o qual foi feito, na medida em que contemplar a vida de um Outro que, tendo se encarnado e nascido em meio a este mundo, disse de si mesmo: "Eu sou o Caminho, a Verdade e a Vida” (Jo 14, 6), fazendo de si o modelo perfeito do homem completo. Por isso também, toda a Terceira e Quarta Semanas serão marcadas pela contemplação da vida de Cristo: para que o jesuíta se converta, ele também, em figura Christi, pela incorporação daquelas imagines agentes nas quais se configuram os episódios da vida do Filho de Deus Encarnado - o Verbum caro.

Passo a passo, Inácio - a experiência-modelo que propõe com a própria vida - vai conduzindo o jesuíta através de uma via cujo fim último será aquela contemplatione Dei que é a suma felicidade do homem, a consolação final, a realização definitiva, como veremos melhor a seguir.

\section{O conhecimento de si nas cartas dos indipetentes}

Sem dúvida, na leitura das Indipetae, salta às vistas, especialmente na estrutura argumentativa utilizada pela maioria dos indipetentes, a preocupação em descrever como se deu o processo de discernimento dos espíritos ou de eleição. Nesse sentido, inúmeros são os exemplos de uso dos topoi aqui analisados.
A começar pela tópica do desejo, que aparece em todas as partes das cartas, de maneira igual ao longo dos anos (no caso das cartas analisadas do ponto de vista macro-histórico), até a tópica da inspiração que só aparece duas vezes e sempre na captatio benevolentiae ${ }^{9}$, passando pelos termos e expressões mais gerais que denotam que quase sempre estão mais presentes na narratio, com freqüência também na petitio, quando é o caso de reafirmar a indignidade e a falta de virtudes.

É bastante evidente, entretanto, a recorrência da tópica do desejo na narratio. O que não é de se estranhar, dado que se trata daquela parte da carta onde o indipetente relata a história do desejo e do trabalho de discernimento de sua origem. Neste relato, o jesuíta coloca ao lado do desejo a vocação, que só é verificada a partir da aplicação das potências da alma (os sentidos e a razão) e do conhecimento por experiência, e a partir de constantes trabalhos de consideração e de encomenda a Deus nas orações e exercícios espirituais, além de sua diferenciação com as tentações e com as paixões desordenadas que se identificam no trabalho de discernimento.

Quanto à captatio benevolentiae, ao lado do desejo os termos mais freqüentes, além da tópica da vocação, são a afirmação da própria indignidade e do trabalho de encomenda a Deus, e a urgência de comunicação das razões da escrita da carta. Dinâmica que se repete com ligeiras diferenças na petitio e na conclusio.

Por exemplo, Seraphin Bonaventura Coçar afirma que os desejos que sente foram dados por "Nuestro Señor (...) cuando me llamo por su infinita bondad a la Compañia”. Segundo ele, a fim de verificar a origem divina do chamado, passou a considerar que se tratava apenas de "fervores de cazuela, y que Dios no me llama (...) y que es tentación”; as experiências que fez a partir daí lhe permitiram chegar à conclusão segura de que os desejos

Como por lo mucho que me ayudan para perfecionarme en la virtud me dan tales prendas de ser llamamiento y vocación de Dios Nuestro Señor, essa aunque no tuviesse tanta salud como tengo ni tanta virtud como para tal empresa es menester so pena de mentir al Spiritu Santo, me obligan a que confiado que su infinita misericordia suplira lo que en mi falta cuando fuere su voluntad que esto se me conceda con resignacion pida a Vuestra Paternidad me enbie al Japón. (ARSI, Indipetae Hispanae, FG 758, carta n. 4)

É interessante notar também como - não só o jovem em questão, mas - praticamente todos os indipetentes insistem em expressões descritivas de sua pouca virtude, de seu pouco preparo espiritual ou de suas capacidades físicas e intelectuais, bem como dos trabalhos a que estão ou não estão preparados: "con todos me hallo bien (...) mi poca virtud la tengo bien conocida”, afirma Coçar; "escribí a Vuestra Paternidad lo que yo sentía de mi” (ARSI, Indipetae Hispanae, FG 758, carta n. 80), confirma Bernardo Matias; Juan Augustin Castangia se pergunta o que Deus pode fazer "por medio de este indiño y ruin instrumento" (ARSI, 
Indipetae Hispanae, FG 758, carta n. 168) que é ele mesmo; Joan Sotalell diz conhecer em sua alma "grande ventaja en mortificar los vicios y pasiones desordenadas" (ARSI, Indipetae Hispanae, FG 758, carta n. 338); Balthasar de Torres ao descrever sua condição na Companhia diz que tem "edad de 20 a 21 años despues de cinco, que ha que entre en la Compañia, de buenas fuerças, y salud; oygo al $4^{\circ}$ año de la phylosophia" (ARSI, Indipetae Hispanae, FG 758, carta n. 13); o irmão coadjutor Domingo Tafalla, a fim de convencer o Superior Geral acerca do quão interessante é que seja enviado, fala daquele aspecto de si mesmo que mais pode ajudar no trabalho na China:

El P.e Rogerio me ha animado mucho, ý me ha dicho que era el mejor tiempo de mi edad para ýr ý aprender la lengua china que no tengo mas de veynte o veynte un años y porque confio que Vuestra Paternidad como à Padre me ha de consolar no me alargo mas. (ARSI, Indipetae Hispanae, FG 758, carta n. 136)

Este é um trecho bastante significativo dentre os diversos exemplos que poderíamos elencar: aqui o conhecimento de si se dá por intermédio de um terceiro a quem se confia o indipetente. Dessa forma, compreende-se como o trabalho de discernimento dos espíritos não era um trabalho solitário: o jesuíta se sabe como tal num relacionamento concreto de características muito próprias. ${ }^{10}$

Outro aspecto, já apontado por Massimi e Prudente (2002), respeita às qualificações que, na maior parte das vezes, acompanha a palavra desejo: encendido desseo, desseo fervoroso, antiguos deseos, muy grandes deseos, eficaces deseos, buenos deseos, deseo firme, grande deseo, desseos muy encendidos. Em todas as vezes é sempre qualificado de maneira a reforçar sua importância (Massimi \& Prudente, 2002): o fato de serem grandes, incendidos, antigos, bons ou fervorosos, garante ao indipetente a origem divina do desejo, o que se confirma, por exemplo, no texto de Coçar que diz que Deus lhe dá um "desseo fervoroso, que como luz del cielo deshaze en mi alma aquellas tinieblas y razones, dexandome muy consolado". Também Balthasar Torres faz uso de recurso semelhante quando explica, em carta, que algumas vezes sentiu se resfriar o desejo, por medos e outras adversidades, porém, "acudía Nuestro Señor con mas ferborosos deseos de los ordinarios, prometiendome ayuda de su divina mano" (ARSI, Indipetae Hispanae, FG 758, carta n. 13). Antonio Perez, por sua vez, contando "llanamente la verdad" (ARSI, Indipetae Hispanae, FG 758, carta n. 43) da história de seus antigos desejos, confirma que se trata de vocação de Deus porque, quando estudava em Cordona, tendo ouvido a história de Francisco Xavier, viu um desejo de imitar seus passos crescer em si mesmo que em nada diminuía diante das "dificultades que se me representaban". Outro jovem jesuíta - de 21 anos -, Juan de Avila escreve dizendo que

es tan grande el desseo, que de yr a padeçer por Christo y emplear mi vida en esta empresa, me da sua Magestad que quando lo pienço rebiento en lagrimas, y dame Dios dello tanta confiança, que reparando enello despaçio, lo tengo por tan cierto, como si lo viesse ya cumplido. (ARSI, Indipetae Hispanae, FG 758, carta n. 126)

De fato, esses adjetivos nada mais significam que uma confirmação de que não se tratam de desejos desordenados. O mesmo Juan de Ávila, na sequiência do trecho anterior, escreve que "quando en la mortificaçion de mis passiones, $y$ camino de la perfecçion se me offreçe alguna difficultad, el mejor remedio que tengo, y con que me animo mucho, es pensar que me voy preparando para esto". Trata-se de um desejo que remedia, que auxilia no trabalho de mortificação das paixões desordenadas. Leon Ximenes fala de grandes desejos de ir ao Peru onde se "padecen muchos trabajos y incomodidades en la comida habitacion, y cama, y que el trato mio ha de ser con gente ruda, con negros, y gente barbara" (ARSI, Indipetae Hispanae, FG 758, carta n. 290) e continua pouco adiante, escrevendo que Deus "me dara fuerças para ello, pues el me llama y tambien espero me dara perseverancia en mi buen proposito": não fosse um chamado de Deus, desejaria tantos incômodos? Ou ainda Joan Sotalell, que deseja oferecer a "Christo Nuestro Señor (...) por mi alma una perfeita obediencia y abnegacion grande en todas las cosas, y por el cuerpo, el mas horible y cruel martyrio, que hasta ahora se a padecido, ni los tyrannos an inventado" (ARSI, Indipetae Hispanae, FG 758, carta n. 338). Um tal desejo só se compreende quando está devidamente ordenado por uma obediência ao factus último identificado no constante exercício de discernimento a que eram educados, ordenado, finalmente, por uma obediência ao chamado de tudo "hazer por amor del mesmo Señor".

\section{Uma análise micro-histórica: as cartas de Juan Bravo}

Do ponto de vista da análise micro-histórica, as cartas de Juan Bravo nos oferecem alguns aspectos interessantes a serem observados: ao longo dos três anos de escrita (apenas utilizando as cartas a que tivemos acesso), observamos uma paulatina simplificação da forma de argumentação utilizada nas cartas. Enquanto que na primeira, há um evidente cuidado com a estruturação retórica (até mesmo, a captatio benevolentiae está separada do restante da carta), nas cartas seguintes, Juan Bravo, além de diminuir a extensão da carta, simplifica sua forma até o ponto de, na última, narratio e captatio benevolentiae se confundirem numa espécie de grande petitio.

Na primeira de suas Indipetae (que cremos ser, de fato, a primeira carta que escreve ao superior geral ${ }^{11}$ ), Juan Bravo não menciona, na primeira parte da carta, nada acerca do seu desejo. Apenas iniciada a narratio, declara qual é o desejo que sente e já afirma que se trata de vocação comunicada por "su divina Magestad". Em seguida, começa a descrever todo o trabalho de discernimento dos espíritos a que se dedicou: "my acudi a la oraçion, comulgandome algunas vezes, y haziendo otras penitençias a este fin, procure tanbien ayudarme de las oraçiones de los otros", e mais à frente diz também que "hize refflexion sobre my mismo y vy dos cosas las quales sin pretendello me descubrieron lo que yo deseava 
saber". O aspecto mais evidente de sua narratio é a recorrência não do termo desejo, mas do termo vocação e de termos semelhantes - comunicação, chamado, entre outros. $\mathrm{O}$ indipetente parece querer deixar bastante claro que está perfeitamente desenganado de que o desejo é "Ilamamento", e de que "este llamamiento es divino". Nas duas últimas partes de sua primeira carta, nenhum lugar-comum que se relacione ao conhecimento de si volta a aparecer.

Será nas cartas seguintes que Juan Bravo começará, não tendo obtido resposta do padre geral, a valorizar, na captatio, o topos do desejo: "mas he tardado en renovar a Vuestra Paternidad la memoria de mys desseos" (ARSI, Indipetae Hispanae, FG 758, carta n. 404), ou "mas a menudo quisiera yo refrescar a Vuestra Paternidad la memoria de mys deseos" (ARSI, Indipetae Hispanae, FG 759, carta n. 4). Também nesta parte de suas cartas seguintes, o indipetente procura expressar com mais eficácia sua indignidade por tão "fuertes $y$ vigorosos" desejos, "aun para quien en vez de benefficios tenia mereçidos muchos açotes y castigos". Nas pequenas narrationes que faz nestas duas cartas seguintes, o jovem jesuíta procura mais demonstrar o quão desenganado está e, portanto, o quão certo se encontra da origem divina de seu desejo, que descrevê-lo, ou aos trabalhos eletivos a que se tenha dedicado.

É na última de suas cartas que encontramos o dado mais significativo: nela, a recorrência aos termos vinculados à urgência de uma experiência de filiação e conseqüente identificação com o corpo institucional da Companhia de Jesus fica evidente. Juan Bravo, como que vai, pouco a pouco, fazendo coincidir seus "deseos de yr a las Yslas del Japon para derramar en ellas el sudor y la sangre", com seu chamado à ordem religiosa fundada por Inácio de Loyola (referido na primeira carta): ir em missão é mais que satisfazer um desejo pessoal, é corresponder às expectativas do "Paternal affecto y amor" do superior geral, em quem - ele confia! - reina um desejo "de fomentar, y alentar qualquier buen parto de sus espirituales hijos". Sua carta-pedido é toda ela dirigida ao prepósito a quem - ele espera! - Deus pagará "con eternos dones los dichosos trabajos que por sus hijos toma y en particular el que por este indigno tomare" (ARSI, Indipetae Hispanae, FG 758, carta n. 404)... e Deus pagará, por que foi Ele quem deu a Juan Bravo esses desejos: trazer para a luz os desejos e endereçá-los "para mayor gloria del que se los dio" é tarefa do superior.

\section{Conclusão}

Assim, pudemos ver como o "conhecimento de si" é momento fundamental no trabalho de eleição a que são educados e formados os jesuítas. Mas, mais do que isso, verificamos como esta tópica pressupõe uma unidade indissolúvel entre corpo e alma, de forma que, falar de conhecimento de si não significa apenas uma cognição estanque de estruturas psíquicas, de capacidades físicas ou comportamentos de for- ma isolada. Sem dúvida que muitas das psicologias contemporâneas, ao trabalharem desta maneira, têm a justa intenção de conhecer adequada e cientificamente - segundo certos imperativos epistemológicos muito bem definidos e corretamente aplicados - aquilo sobre o que se debruça como objeto de seu saber. Porém, a possibilidade de, escavando o terreno onde a psicologia moderna plantou suas raízes, reconhecer uma experiência de consideração do ser humano tal como a que acabamos de descobrir, interessa sobremaneira se, mudando o foco da pergunta inicial, colocarmos a própria psicologia como sujeito deste conhecimento de si: o que é a psicologia? Estaríamos, porém, adentrando o mundo da epistemologia. Resta-nos apenas provocar um debate indiscutivelmente importante e fonte de deleite para os que se interessam por esta pergunta, lançando mão do juízo que Wertheimer (1998, citando Griffith, 1921), nos lembra: se a ciência da psicologia "deve assumir a responsabilidade da maturidade, precisa se voltar seriamente para sua história" (p. 37). E, sem dúvida, o trabalho de escavo das origens, o trabalho de apresentação, de trazer à tona o "período gestacional” da psicologia só terá valor se contribuir a repensar o que, há muito tempo, vimos dando por óbvio. Ou a consideração desta concepção da experiência humana que aprendemos dos jesuítas, serve de provocação à evidente exigência de unidade para uma constituição, sobre bases sólidas, do estatuto epistemológico da psicologia contemporânea, ou será apenas fruto de uma curiosidade ou erudição.

Tornemos, porém, ao que ficou evidenciado pela análise dos documentos, tendo como ponto de referência a tópica em discussão: para a psicologia filosófica aristotélico-tomista da Companhia de Jesus, nos séculos XVI e XVII, falar de conhecimento de si é, sempre, considerar uma unidade não apenas na pessoa, mas da pessoa com a realidade espaçotemporal que a circunda, de modo que o mundo e as criaturas todas, se tornam realidades sacramentais, ou seja, sinais de Algo Outro. Estamos diante de uma realidade inteiramente diferente da nossa. A discussão não pode, pois, nos levar a juízos do tipo "esta posição é mais coerente do que aquela", mas pode suscitar o assombro necessário para dar partida a toda busca verdadeira.

Nesse sentido, o estudo histórico aqui realizado nos aponta o imperativo de se evidenciar esta noção de homem, que é subjacente a uma certa maneira de considerar a prática do conhecimento de si mesmo e seu uso numa determinada perspectiva - "psicologia filosófica". Trata-se daquela visão de homem que sustenta o "dinamismo psíquico" descrito nas Indipetae. Nela, o aspecto mais surpreendente é a consideração da totalidade dos fatores que compõem a pessoa: corpo, sensações, afetos, juízos.

Esperamos, tendo dado voz a esta realidade tão distante de nós no tempo e na mentalidade, ter contribuído a que, superando a estraneidade desta distância, nos deixemos provocar pelas perguntas que nascerão, com certeza, da progressiva amizade com esta realidade outra. 


\section{Agradecimento}

Os autores agradecem o apoio financeiro da CAPES à tese de doutorado da qual este artigo foi adaptado.

\section{Referências}

Aquaviva, C. (1583). Lettera del Nostro Padre Generale Claudio Acquaviva. Sopra la Rinovatione dello spirito à Padri \& Fratelli della Compagnie [29 de setembro de 1583]. Roma. (texto original manuscrito)

Arias, F. (1600). Profitto spirituale, nel qual s'insegna à fare acquisto delle virtù, \& progresso nello spirito. Del M.R.P. Francesco Arias della Compagnia di Giesu. Tradotto della lingua Spagnuola, dal Cavaliere Fra Giulio Zanchini da Castiglionchio. Milano: Stampa del q. Pacifico Pontio, Impressore Archiepiscopale. (Texto original publicado em 1588)

Archivum Romanum Societatis Iesu/ ARSI, Indipetae Hispanae, FG 758, carta n. 4. Archivum Romanum Societatis Iesu/ ARSI, Indipetae Hispanae, FG 758, carta n. 13. Archivum Romanum Societatis Iesu/ ARSI, Indipetae Hispanae, FG 758, carta n. 43. Archivum Romanum Societatis Iesu/ ARSI, Indipetae Hispanae, FG 758, carta n. 80. Archivum Romanum Societatis Iesu/ ARSI, Indipetae Hispanae, FG 758, carta n. 126. Archivum Romanum Societatis Iesu/ARSI, Indipetae Hispanae, FG 758, carta n. 136. Archivum Romanum Societatis Iesu/ ARSI, Indipetae Hispanae, FG 758, carta n. 168. Archivum Romanum Societatis Iesu/ ARSI, Indipetae Hispanae, FG 758, carta n. 290. Archivum Romanum Societatis Iesu/ ARSI, Indipetae Hispanae, FG 758, carta n. 329. Archivum Romanum Societatis Iesu/ ARSI, Indipetae Hispanae, FG 758, carta n. 338. Archivum Romanum Societatis Iesu/ARSI, Indipetae Hispanae, FG 758, carta n. 404. Archivum Romanum Societatis Iesu/ ARSI, Indipetae Hispanae, FG 759, carta n. 4. Certeau, M. (1982). La fable mystique, 1: XVIe - XVIIe siècle. Paris: Gallimard. Cicéron, M. T. (1966). De l'orateur. Livre deuxième. (E. Courbaud, Trad.). Paris: Société d'édition Les Belles Lettres. (Texto original publicado em 55 a.C.)

Loyola, I. (1991). Écrits (M. Giuliani, Pres. et Dir.). Paris: Desclée de Brouwer; Bellarmin (Collection Christus, 76, Textes). (Textos originais do século XVI)
Marin, L. (1996). Le Récit, réflexion sur un testament. In L'écriture de soi: Ignace de Loyola, Montaigne, Stendhal, Roland Barthes (pp. 137-155). Paris: Presses Universitaires de France.

Massimi, M., \& Prudente, A. B. (2002). Um incendido desejo das Índias... São Paulo: Loyola.

Nieremberg, J. E. (1645). Honor del gran patriarca san Ignacio de Loyola, fundador de la Compañia de Iesus, en que se propone sua vida, y la de su Dicipulo el apostolo de las Indias S. Francisco Xavier. Con la milagrosa Historia del admirable Padre Marcelo Mastrilli, y las noticias de grand multitud de Hijos del mismo S. Ignacio, varones clarissimos en santidad, dotrina, trabajos, $y$ obras maravillosas en servicio de la Iglesia. Madrid: Maria de Quiñones.

Nieremberg, J. E. (1957). Obras escogidas del R. P. Juan Eusebio Nieremberg. In E. Zepeda-Henriquez (Org.), Biblioteca de Autores Españoles, desde la formación del lenguaje hasta nuestros dias (Tomo 104). Madrid: Atlas. (Textos originais publicados no século XVII)

Pécora, A. (1988). O demônio mudo. In A. Novaes (Org.), O olhar (pp. 301316). São Paulo: Companhia das Letras.

Pécora, A. (1994). Teatro do Sacramento: a unidade teológico-retórico-política dos sermões de Antonio Vieira. São Paulo: EDUSP.

Pécora, A. (1998). Les sermons funèbres du padre Vieira. In K. Q. Mattoso (Org.), Naissance du Brésil moderne (pp. 194-202). Paris: Presses de l’Université de Paris-Sorbonne.

Tertullien (1906). Traité de la pénitence (P. de Labriolle, Org.). Paris: A. Picard et fils. (Texto original publicado no século II)

Vieira, A. (1993). Sermões. Porto: Lello e Irmão.

Villanueva, M. (1608). Libro de oracion mental. Compuesto por el Padre Melchior de Villanueva, de la Compañia de Iesus. Toledo: Pedro Rodriguez impressor del Rey nuestro Señor.

Wertheimer, M. (1998). Pesquisa histórica - por quê? In J. Brozek \& M. Massimi (Orgs.), Historiografia da psicologia moderna - versão brasileira (pp. 21-42). São Paulo: Unimarco/ Loyola. 
${ }^{1} \mathrm{O}$ presente artigo é derivado da tese de doutorado Liberdade e indiferença: a "experiência-modelo" jesuítica em cartas de jovens indipetentes espanhóis dos séculos XVI e XVII, defendida pelo primeiro autor, sob orientação da segunda autora.

${ }^{2}$ No início do Relato, por exemplo, Pe. Luís Gonçalves da Câmara conta como “até os 26 anos de vida, ele foi um homem dado às vaidades do mundo; ele se deleitava sobretudo no exercício das armas, com um grande e vão desejo de ganhar honra” (Loyola, século XVI/1991, p. 1019).

${ }^{3}$ O Relato conta que "os desejos de imitar os santos se apresentavam a ele, e ele considerava menos as circunstâncias que o fato de se prometer, assim, com a graça de Deus, fazer como eles tinham feito” (Loyola, século XVI/ 1991, p. 1022).

${ }^{4}$ Assim aparece no Relato, por exemplo: “ora, no tempo de sua prisão em Salamanca, os mesmos desejos não lhe faltavam de ser útil às almas e, para isso, estudar primeiro, reunir alguns homens que tivessem o mesmo desígnio e guardar aqueles que ele tinha” (Loyola, século XVI/1991, p. 1055).

${ }^{5}$ Assim diz a letra da regra: "É preciso igualmente fazer observar àqueles que se examina, e a isso dar muita importância e preço alto diante de nosso Criador e Senhor, o quanto é uma ajuda e um proveito para a vida espiritual ter em horror, totalmente e não em parte, tudo o que o mundo ama e abraça, e aceitar e desejar com todas as suas forças tudo o que Cristo nosso Senhor amou e abraçou” (Loyola, século XVI/1991, p. 416, Const. $\S 101)$.

${ }^{6}$ Tradução nossa, como em todas as demais transcrições extraídas de Loyola (século XVI/1991) e de outros originais em língua estrangeira.

${ }^{7}$ Nas Regras Gerais tiradas das Constituições, há um ponto que deixa bastante clara essa dinâmica: segundo o autor, antes de tratar qualquer coisa com o Superior, os jesuítas devem se recolher em oração e, “... em seguida, se sentem que devem apresentar o negócio àquele que tem o cargo, que o façam. A outra coisa que devem observar: depois de ter apresentado o negócio de viva voz ou brevemente por escrito (para que não se esqueça), que abandonem todo o cuidado aos superiores e estimem que tudo o que ordenarem será o melhor. Que não repliquem nem façam instâncias, nem por eles mesmo nem por nenhuma outra pessoa, quer os superiores aceitem o que foi pedido ou não. Que todos se persuadam que aquilo que seu superior, estando informado, ordenar será aquilo que convém mais ao serviço divino e a seu maior bem em nosso Senhor” (Loyola, século XVI/1991, p. 614).

${ }^{8}$ Cinco são os pontos. “O primeiro ponto: dar graças a Deus nosso Senhor pelos benefícios recebidos. O segundo: pedir a graça de conhecer seus pecados e de os rejeitar. O terceiro: pedir conta à sua alma, desde a hora em que se levantar até o presente exame, hora após hora, ou período após período, primeiro dos pensamentos, depois das palavras, depois das ações, segundo a mesma ordem que foi indicada para o exame particular. O quarto: pedir perdão das faltas a Deus nosso Senhor. O quinto: formar o propósito de se emendar com sua graça” (Loyola, século XVI/1991, p. 76, EE. 73).

${ }^{9}$ Salutatio, captatio benevolentiae, narratio, petitio e conclusio - termos que aparecerão daqui para frente - são nomes das partes da correspondência epistolar, conforme o modelo clássico ciceroniano, mantido na tradição da ars dictaminis medieval e preservado no seio da igreja e das ordens religiosas entre os séculos XVI e XVIII na Europa.

${ }^{10}$ É interessante observar como, de fato, essa descrição, se não considerada em seu dinamismo, pode nos levar ao erro da análise estanque: como se cada um desses conjuntos de lugares-comuns fossem independentes e não descrevessem um continuum de vivido.

${ }^{11}$ Logo na captatio benevolentiae ele afirma: “Con mucho consuelo myo escrivo esta a Vuestra Paternidad parte por ser la occasion con que la escrivo tal quales, parte tanbien por que me da no pequeña alegria ver que siendo la primera que a Vuestra Paternidad escrivo sea con tal occasion” (ARSI, Indipetae Hispanae, FG 758, carta n. 329).

Paulo Roberto de Andrada Pacheco, doutor em Psicologia pela Universidade de São Paulo, é professor no Departamento de Educação da Universidade Federal de Ouro Preto, Mariana, MG. Endereço para correspondência: Rua Cônsul Robert Levy, 957 (São Bento); Belo Horizonte, MG; CEP 30350-710. Tel.: (31) 33372721. E-mail: paulopac@yahoo.com.br ou paulopac@ichs.ufop.br Marina Massimi, Livre Docente pela Universidade de São Paulo, é professora associada da Universidade de São Paulo - Ribeirão Preto. 